\title{
e-Relationships for e-Readiness: Culture and corruption in international e-B2B
}

\author{
Pierre Berthon $^{\mathrm{a}, *}$, Leyland Pitt ${ }^{\mathrm{b}}$, Jean-Paul Berthon ${ }^{\mathrm{c}, \mathrm{d}}$, Colin Campbell ${ }^{\mathrm{e}}$, Des Thwaites ${ }^{\mathrm{f}}$ \\ ${ }^{\mathrm{a}}$ McCallum School of Business, Bentley College, Waltham, MA, USA \\ ${ }^{\mathrm{b}}$ Segal Graduate School of Business, Simon Fraser University, Vancouver, BC, Canada \\ ${ }^{\mathrm{c}}$ Richmond University London, UK \\ ${ }^{\mathrm{d}}$ Lulea University, Sweden \\ e Simon Fraser University, Vancouver, BC, Canada \\ ${ }^{\mathrm{f}}$ University of Leeds, UK
}

Received 1 October 2006; received in revised form 1 May 2007; accepted 1 June 2007

Available online 7 November 2007

\begin{abstract}
The role of electronic networks in B2B relationships has been growing exponentially. From massive internet B2B exchanges to tiny RFID chips, B2B is increasingly becoming e-B2B. Whilst e-B2B has been explored intra-nationally, its international counterpart is less well documented; as has been the role that culture might play in the development of international e-B2B relationships. In this paper we address this important issue of international e-business relationships. Specifically we explore the interconnection between national e-readiness and cultural values, and address the research question: How do cultural values impact a nation's readiness to engage in e-business? Drawing upon international surveys we link cultural values with national e-business infrastructure. Our findings suggest an intriguing link between cultural values and a nation's readiness for e-B2B. From these results we develop managerial recommendations and extrapolate research opportunities.

(C) 2007 Elsevier Inc. All rights reserved.
\end{abstract}

Keywords: E-readiness; Internet; B2B; Culture; Corruption; International

\section{Introduction}

The role of electronic networks in B2B relationships has been growing exponentially. From massive internet B2B exchanges to tiny RFID chips, B2B is increasingly becoming e-B2B (cf. Economist, 2006). For example, over the past few years a plethora of trans-national exchanges have emerged, from open, public exchanges such as Covisint (www.covisint.com), through delimited, consortia exchanges such as Aeroxchange (aeroxchange. com), to the closed, private exchanges such as those run by WalMart and Dell. These latter companies, as well as the likes of Boeing and Target, mandate suppliers to embed goods and components with RFID chips to create an electronically managed trans-national supply chain (Brass, 2006).

\footnotetext{
* Corresponding author.

E-mail address: pberthon@bentley.edu (P. Berthon).
}

Despite this, the specific trans-national aspect of e-B2B although arguably it's sine qua non, has perhaps received less formal academic attention than other aspects of e-commerce. Conceptual endeavors in this field do exist in the works of Samiee (1998), Avlonitis and Karayanni (2000), Porter (2001) and Karavdic and Gregory (2005). Furthermore, technical issues such as trans-national e-enabled supply chains (Iyer, Germain, \& Frankwick, 2004), enterprise resource planning (Burn \& Colin, 2005) and multi-lingual web sites (Tiessen, 2004) have begun to be explored. However, less attention has been given to the question of what makes industrial firms in other countries ready or not for e-B2B relationships, and what will make these relationships work best.

A number of authors have begun to explore the barriers to transnational e-commerce relationships (e.g. Eid, Trueman, \& Ahmad, 2002). A range of objective, technical issues such as networkinfrastructure and computer literacy have become apparent (cf. 
Reddy \& Iyer, 2002), as well as a number of subjective factors, such as culture (Yap, Das, Burbridge, \& Cort, 2006) and trust (Aljifri, Pons, \& Collin, 2003; Olson \& Olson, 2000).

Several institutions have tried to capture countries' amenability or readiness for e-commerce relationships, including the International Trade Forum and the Economist Intelligence Unit (cf. Rao, 2003). However these indicators, by focusing primarily on national, objective measures only tell part of a more complex story. Before international B2B marketers can understand a potential relationship partner in another country, they need to have a good basic comprehension of the society itself, with regard to issues ranging from relationship-values to wider national culture. Put simply, before a B2B marketer can judge a potential partner's readiness for an e-relationship, they need to have a good grasp of the partner's country's e-readiness - both in terms of "hard", infrastructure issues to "soft", value issues.

In this paper we address the important issue of international e-business relationships. Specifically we empirically explore the interconnection between national e-readiness and cultural values, and address whether cultural values impact a nation's readiness to engage in e-business. Drawing upon a number of large international surveys we link a country's subjective values with national-level, objective e-business infrastructure. Our findings suggest an interesting link between cultural values and a nation's readiness for e-B2B. From these results we develop managerial recommendations and extrapolate research opportunities.

\section{Research questions}

We address two important research questions in this paper. First, we consider the role that social values play in the development of trans-national e-business. Second, we speculate on the role that corruption in a particular society may play in hindering trans-national e-business relationships. From the very earliest days of international business as a subject discipline, scholars have been interested in cultural differences (e.g. Joynt \& Warner, 1985), and how they impact on both the ways firms are managed, and in which customers behave. However, less attention has been given to how a nation's culture influences the development of e-business in that country, and what that in turn means to traders from other nations who desire to do business with it.

It is well documented that business in general is hampered by on the one hand by corruption and the other hand by absence of trust (Lambsdorff, 2007). Recently the negative effect of corruption and trust on e-business has also been explored (Cousins \& Robey, 2005). Whilst corruption and mistrust at a national level may be correlated, trust between parties may become more important in situations where corruption is rampant - and correspondingly less important when institutional corruption is low. Unfortunately, different nations and cultures have different views on corruption - what is viewed as corrupt in one culture might simply be viewed as a way of doing business in another (Khatri, Tsang, \& Begley, 2006; Park, 2003; Sanyal, 2005). This means that the establishment of e-B2B relationships with partners in other countries is impacted on severely by the levels of corruption in them. Indeed, in all likelihood, a readiness for e-relationships (impacted by culture) is therefore not simply a function of the technological readiness of the target nation, but is compounded by corruption (which is also, in turn, impacted by culture). Accordingly, the constructs that we focus on in this study are e-readiness, culture, values, and corruption. These are now discussed in turn.

\section{Constructs}

\section{1. e-Readiness}

The construct of e-readiness is defined as a country's ability to promote and support digital business and information and communications technology (ICT) services; thus a nation's ereadiness is in practice a measure of its e-business environment, a collection of category indicators of how amenable a country is to internet-based opportunities (Economist, 2006). Each year the Economist Intelligence Unit in co-operation with IBM's Institute for Business Value publishes a white paper which ranks the e-readiness of the world's nations (Economist Intelligence Unit, 2006); this report serves as a source of data for our research. Specifically, e-readiness is defined as a weighted function of six categories:

$\mathrm{e}-$ readiness $=\mathrm{fn}\{.25($ Connectivity and technology infrastructure $)$,

.20 (Business environment),

.20 (Consumer and business adoption),

.15 (Legal and policy environment),

.15 (Social and cultural environment),

.05 (Supporting e-services) $\}$

Connectivity and technology infrastructure include such coverage factors as narrow, broadband, PC and mobile-phone penetration, as well as internet affordability and security. The business environment comprises a series of indicators including strength of the economy, political stability, the regulatory environment, taxation, competition policy, the labor market, the quality of infrastructure, and openness to trade and investment. The consumer and business adoption category consists of national spending on information and communications technology as a proportion of GDP, the level of e-business development, the degree of online commerce, the quality of logistics and delivery systems and the availability of corporate finance. The legal and policy environment comprises factors such as overall political environment, policy toward private property, government vision regarding digital-age advances, government financial support of Internet infrastructure projects, effectiveness of the traditional legal framework, laws covering the internet, level of censorship, and ease of registering a new business. The social and cultural environment consists of educational level, internet/web literacy, degree of entrepreneurship, technical skills of the workforce, and degree of innovation. 
Table 1

Sample of the e-readiness data from the Economist intelligence unit (2006) rankings ${ }^{\text {a }}$

\begin{tabular}{|c|c|c|c|c|c|c|c|}
\hline Country & Connectivity & Business environment & Consumer and business adoption & Legal/policy & Socio-cultural & supporting e-services & Total \\
\hline Weight & 0.25 & 0.20 & 0.20 & 0.15 & 0.15 & 0.05 & 1.00 \\
\hline Denmark & 8.70 & 8.77 & 9.45 & 8.70 & 9.40 & 9.25 & 9.00 \\
\hline US & 7.85 & 8.59 & 10.00 & 8.77 & 9.20 & 10.00 & 8.88 \\
\hline Switzerland & 8.50 & 8.56 & 9.45 & 8.24 & 9.20 & 10.00 & 8.51 \\
\hline Sweden & 8.00 & 8.36 & 9.55 & 8.58 & 9.40 & 9.25 & 8.74 \\
\hline UK & 7.90 & 8.57 & 10.00 & 8.42 & 8.20 & 9.25 & 8.64 \\
\hline Netherlands & 8.20 & 8.57 & 9.05 & 8.46 & 8.60 & 9.25 & 8.60 \\
\hline Finland & 7.80 & 8.59 & 9.25 & 8.52 & 8.60 & 9.25 & 8.55 \\
\hline Australia & 7.80 & 8.27 & 8.65 & 9.05 & 9.00 & 9.25 & 8.50 \\
\hline Canada & 7.75 & 8.75 & 8.65 & 8.70 & 7.80 & 9.50 & 8.37 \\
\hline Hong Kong & 8.10 & 8.58 & 9.20 & 9.23 & 6.40 & 8.75 & 8.36 \\
\hline UAE & 5.00 & 7.68 & 5.85 & 6.97 & 6.20 & 7.25 & 6.32 \\
\hline Chile & 4.15 & 7.94 & 5.95 & 7.66 & 6.00 & 6.50 & 6.19 \\
\hline Czech Rep & 4.90 & 7.39 & 6.00 & 6.84 & 5.60 & 7.50 & 6.14 \\
\hline Hungary & 4.80 & 7.34 & 5.85 & 6.86 & 6.00 & 7.50 & 6.14 \\
\hline Poland & 4.30 & 7.28 & 5.05 & 6.46 & 5.80 & 7.50 & 5.76 \\
\hline South Africa & 2.70 & 6.85 & 6.50 & 7.48 & 6.00 & 7.50 & 5.74 \\
\hline Slovakia & 4.05 & 7.35 & 4.50 & 6.38 & 6.40 & 7.00 & 5.65 \\
\hline Malaysia & 4.45 & 7.21 & 5.85 & 5.95 & 4.80 & 5.25 & 5.60 \\
\hline Lithuania & 4.65 & 7.28 & 3.85 & 5.99 & 5.40 & 7.00 & 5.45 \\
\hline Latvia & 3.95 & 7.21 & 3.85 & 6.09 & 5.60 & 7.00 & 5.30 \\
\hline Sri Lanka & 1.55 & 6.13 & 2.95 & 4.96 & 4.20 & 3.50 & 3.75 \\
\hline Nigeria & 1.15 & 6.13 & 2.95 & 4.94 & 5.00 & 4.50 & 3.69 \\
\hline Ukraine & 2.50 & 5.46 & 1.85 & 3.85 & 4.80 & 4.75 & 3.62 \\
\hline Indonesia & 1.70 & 6.41 & 2.80 & 3.24 & 3.00 & 3.75 & 3.39 \\
\hline Algeria & 2.35 & 5.36 & 2.35 & 3.42 & 3.60 & 2.75 & 3.32 \\
\hline Kazakhstan & 2.10 & 5.37 & 1.95 & 3.42 & 3.60 & 3.50 & 3.22 \\
\hline Iran & 2.70 & 4.37 & 2.05 & 2.49 & 4.00 & 3.25 & 3.15 \\
\hline Vietnam & 1.60 & 5.68 & 2.00 & 3.56 & 3.40 & 2.75 & 3.12 \\
\hline Pakistan & 1.50 & 5.12 & 1.95 & 3.90 & 3.20 & 3.50 & 3.03 \\
\hline Azerbaijan & 1.85 & 5.54 & 1.80 & 2.68 & 2.80 & 3.25 & 2.92 \\
\hline
\end{tabular}

a A comprehensive list of e-readiness data can be found via the Economist Intelligence Unit.

Finally supporting e-services comprises availability of ebusiness consulting and technical support services, availability of back-office support, and industry-wide standards for platforms and programming languages (Economist, 2006). A summary of the e-readiness data (the top 10, the middle 10 and the bottom ten countries ranked according to e-readiness) is provided in Table 1.

\subsection{Culture}

The concept of culture has its roots in anthropology and can be traced back to the late nineteenth century (e.g. Taylor, 1871). Since its inception, initially in the field of anthropology and subsequently in sociology, the meaning and definition of the term 'culture' has been emotively disputed. Suffice it to say that there are multiple conceptions of culture (Smircich, 1983) and consequently multiple definitions. On the one hand, culture is viewed as something a society has, whilst on the other hand, it is something that a society is. In this paper we draw upon the work of Eckstein (1988) to define culture as "orientations to action," or "general dispositions to act in certain ways in sets of situations." People acquire such orientations through socialization, where they learn about social norms and expectations regarding acceptable behavior (Eckstein, 1988: 790-91). Here we look at two aspects of a society: cultural values and corruption.

\subsubsection{Values}

Values are ideals that guide or qualify an individual's personal conduct, interaction and involvement with other social actors. Similar to morals, they permit individuals to distinguish what is right from what is wrong, and inform them on how to conduct themselves in different social contexts. Finally, values bestow meaning on action and events. Obviously, values are at the heart of culture, and so when we say that "cultures differ", we are as much saying that cultures differ because cultural values differ. What is "valued" by one culture, might not be esteemed by another. Our perspective on cultural values is based in the work of Inglehart (1990, 1997, 2000) and Inglehart and Long (2002), and specifically the World Values Survey. He distinguishes two key dimensions with regard to values: traditional vs. secularrational and survival vs. self-expression values.

Much of the recent focus of Inglehart's work has been on the World Values Survey (WVS, 2005) a project which coordinates a large international network of social scientists, and that studies values across the world's nations. The first major dimension of cross-cultural variation revealed in the World Values Survey is the traditional vs. secular-rational dichotomy. This axis reflects amongst other things the relative importance of religion in a society. Traditional societies emphasize religion, the importance of the family, deference to authority, absolute standards and traditional values. In contrast secular-rational societies value 
secularism, and are more accepting of phenomena such as divorce, abortion, euthanasia, and suicide. Traditional societies tend to exhibit high levels of national pride while secular-rational societies tend to be weary of nationalistic fervor (WVS, 2005).

The second major dimension of cross-cultural variation in the World Values Survey is the survival vs. self-expression dichotomy. This axis corresponds to the transition from industrial societies to post-industrial societies. In the former, physical security and economic accumulation are emphasized and valued. In contrast in post-industrial societies physical and economic security tend to be taken for granted, and are replaced with an emphasis on subjective well-being, self-expression and quality of life (Inglehart \& Baker, 2000). Fig. 1 is a plot of nations on the two values axes. It is interesting to note that clear clusters emerge along regional and religious lines. The plot is reproduced from Inglehart and Long (2002).

We chose the World Values Survey over other perspectives on culture such as Hall (1959) and Hofstede (1980) for a number of reasons. First, it is by far the largest database of cultural values available and the only survey that has current data for the majority of countries in the world. Second, the World Values Survey adopted a strongly decentralized structure to generate value items: academic representatives from new countries joined in a quasi-democratic network adding items relevant to their culture. In contrast Hofstede (1980) developed all value items himself and used respondents from only one company - IBM; and Hall (1959) as an anthropologist employed personal observation to develop his cultural dimensions.

\subsubsection{Corruption}

The term corruption, derived from the Latin corrumpere to destroy, mar, or break, is defined as the "perversion of a person's integrity in the performance of (esp. official or public) duty or work by bribery, extortion, favor etc." (OED, 1998); it engenders a loss of social integrity and promotes mistrust between social actors. In contrast, trust can be defined as "the willingness of a party to be vulnerable to the actions of another party based on the expectation that the other will perform a particular action important to the trustor, irrespective of the ability to monitor or control that other party." (Mayer, Davis, \& Schoorman, 1995). Trust is essentially a mutual perception of integrity on the part of social actors. Corruption, on the other hand, is the violation of trust, and its core meaning is centered on injustice (Génaux, 2004). Social trust and corruption are often conceived as existing in an inverse relationship to one another (Fukuyama, 1995), although as pointed out earlier this is not always the case.

To measure corruption, we draw upon the work of Transparency International, who has for a number of years published a "Corruption Perceptions Index" (CPI) (Transparency International, 2006). The CPI is essentially a "poll of polls" derived from multiple sources: the general public, resident and non-resident business people, and country experts. Countries are scored on a 0 to 10 scale, where the least corrupt countries have the highest scores, and the most corrupt the lowest scores. Table 2 is a sample of the ratings list of Transparency International, showing the 10 least corrupt and the most corrupt countries for 2005.

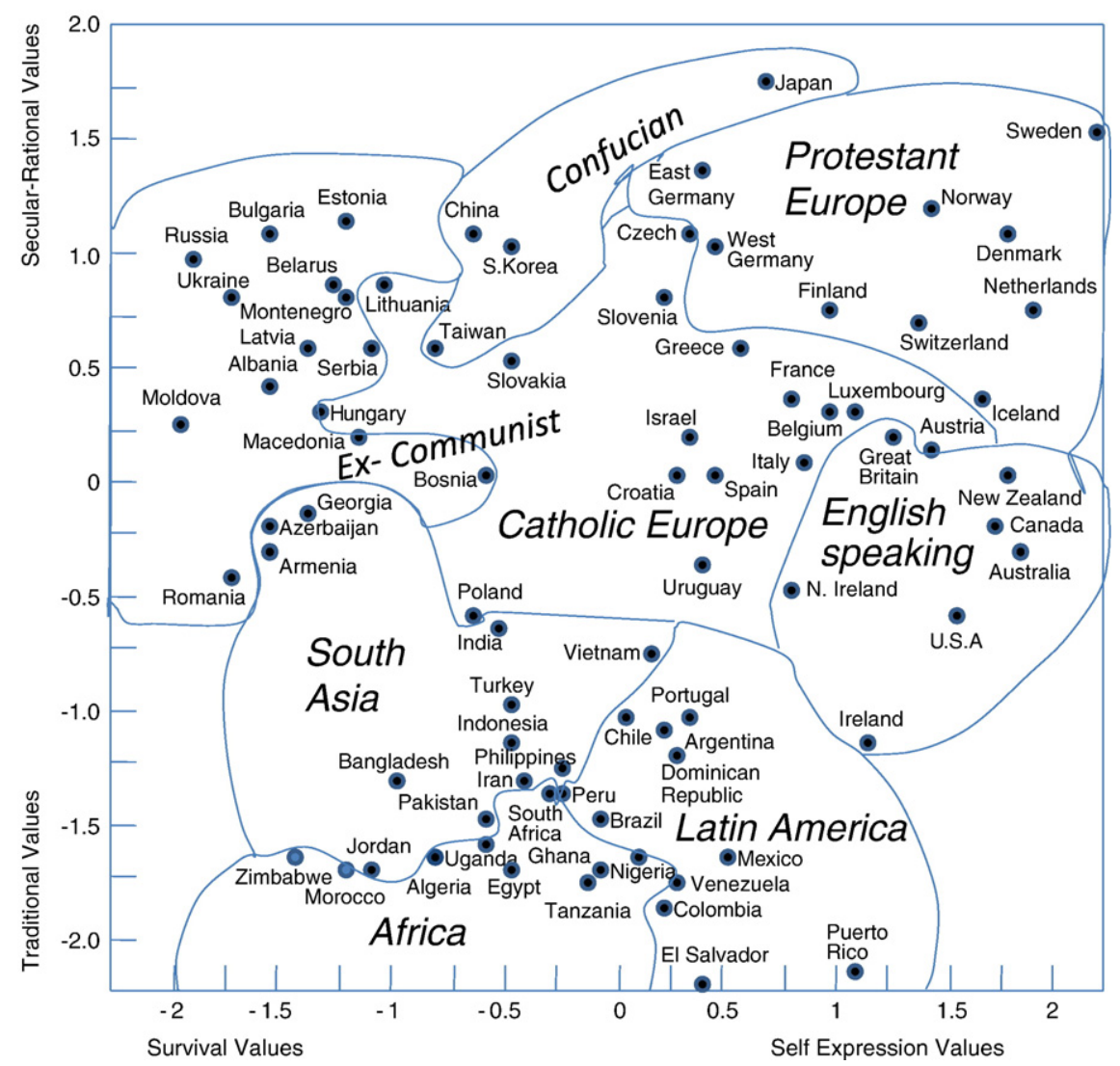

Fig. 1. The Inglehart values map. 
Table 2

Corruption around the globe (Transparency International, 2005) ${ }^{\mathrm{a}}$

\begin{tabular}{|c|c|c|c|}
\hline Country rank & Country & 2005 CPI score ${ }^{b}$ & Confidence range $^{c}$ \\
\hline 1 & Iceland & 9.7 & $9.5-9.7$ \\
\hline \multirow[t]{2}{*}{2} & Finland & 9.6 & $9.5-9.7$ \\
\hline & New Zealand & 9.6 & $9.5-9.7$ \\
\hline 4 & Denmark & 9.5 & $9.3-9.6$ \\
\hline 5 & Singapore & 9.4 & $9.3-9.5$ \\
\hline 6 & Sweden & 9.2 & $9.0-9.3$ \\
\hline 7 & Switzerland & 9.1 & $8.9-9.2$ \\
\hline 8 & Norway & 8.9 & $8.5-9.1$ \\
\hline 9 & Australia & 8.8 & $8.4-9.1$ \\
\hline 10 & Austria & 8.7 & $8.4-9.0$ \\
\hline \multirow[t]{7}{*}{144} & $\begin{array}{l}\text { Congo, } \\
\text { Democratic Republic }\end{array}$ & 2.1 & $1.8-2.3$ \\
\hline & Kenya & 2.1 & $1.8-2.4$ \\
\hline & Pakistan & 2.1 & $1.7-2.6$ \\
\hline & Paraguay & 2.1 & $1.9-2.3$ \\
\hline & Somalia & 2.1 & $1.6-2.2$ \\
\hline & Sudan & 2.1 & $1.9-2.2$ \\
\hline & Tajikistan & 2.1 & $1.9-2.4$ \\
\hline 151 & Angola & 2.0 & $1.8-2.1$ \\
\hline \multirow[t]{3}{*}{152} & Cote d'Ivoire & 1.9 & $1.7-2.1$ \\
\hline & Equatorial Guinea & 1.9 & $1.6-2.1$ \\
\hline & Nigeria & 1.9 & $1.7-2.0$ \\
\hline \multirow[t]{3}{*}{155} & Haiti & 1.8 & $1.5-2.1$ \\
\hline & Myanmar & 1.8 & $1.7-2.0$ \\
\hline & Turkmenistan & 1.8 & $1.7-2.0$ \\
\hline \multirow[t]{2}{*}{158} & Bangladesh & 1.7 & $1.4-2.0$ \\
\hline & Chad & 1.7 & $1.3-2.1$ \\
\hline
\end{tabular}

${ }^{\text {a }}$ A comprehensive list of corruption scores by country can be found at http:// www.transparency.org/policy_research/surveys_indices/cpi/2005.

${ }^{\mathrm{b}}$ CPI Score relates to perceptions of the degree of corruption as seen by business people and country analysts and ranges between 10 (highly clean) and 0 (highly corrupt).

${ }^{c}$ Confidence range provides a range of possible values of the CPI score. This reflects how a country's score may vary, depending on measurement precision. Nominally, with $5 \%$ probability the score is above this range and with another $5 \%$ it is below. However, particularly when only few sources $(n)$ are available an unbiased estimate of the mean coverage probability is lower than the nominal value of $90 \%$.

In summary, we are suggesting that the choice of a country in which to do business for an e-B2B marketer will be determined by three factors, namely, (a) that country's e-readiness, which will determine the ease with which a business relationship can be conducted; (b), that country's values, for values need to be understood as a fundamental facet of culture; and (c), the level of corruption in that country, for it is far easier to manage an erelationship in an atmosphere of trust than one where one player doubts the integrity of the other. While e-readiness might at first glance appear to be merely a technological issue, we propose that it is as much a facet of cultural values and attitudes towards corruption. In that sense, we hypothesize a strong and significant causal relationship between cultural values and corruption on the one hand, and a nation's e-readiness on the other.

\section{Results}

The data for the predictor values in our study consisted of the most recent data on world values, broken down by country, from the World Values Survey (WVS, 2005), and the Transparency International Global Coalition Against Corrup- tion's most recent data on corruption, also broken down by country (CPI, 2005). The data for the criterion variable were the 2006 e-readiness data from the Economist Intelligence Unit (Economist Intelligence Unit, 2006). To test our hypotheses we analyzed the data using ordinary-least squares multiple regression. The results are summarized in Table 3.

As can be observed, the model yielded an adjusted $R^{2}$ of .76, and thus over three quarters of the variance in a country's ereadiness can be explained by its cultural values and propensity toward corruption. The survival vs. self-expression values dimensions of the World Values Survey had a significant impact on e-readiness $(t=2.33, p<.05)$, as had the traditional vs. secularrational values dimension of the Survey $(t=2.58, p<.05)$. The perceived corruption index also has a significant impact on ereadiness $(t=3.58, p<.05)$. From the standardized beta coefficients, we can deduce that corruption has the greatest impact on ereadiness, followed by the survival vs. self-expression values dimension, and then the traditional vs. secular-rational values dimension. However taken together the two values dimensions had a greater combined impact on e-readiness than corruption. Finally, the variance inflation factors for the independent variables suggest that although the independent variables are correlated, multicolinearity is not a problem.

Finally, predicted total e-readiness is given by:

$$
\begin{aligned}
\mathrm{e}-\text { readiness }= & \left(0.58^{*} \text { Survival vs. Self-expression }\right) \\
& +(0.46 * \text { Traditional vs. Secular }) \\
& +\left(0.433^{*} \text { Corruption }\right)+4.43 .
\end{aligned}
$$

A visual plot of the regression model's predicted e-readiness vs. actual e-readiness for each of the 62 countries we included in our analysis is provided in Fig. 2.

To both visually illustrate and to simplify interpretation of the results, a discriminant analysis was performed on the major

\begin{tabular}{|c|c|c|c|c|c|c|}
\hline \multicolumn{7}{|c|}{ Dependent variable: total e-readiness } \\
\hline \multicolumn{7}{|c|}{ Predictors: (constant), corruption, TradSecVal, SrvSExprsVal } \\
\hline$R$ & \multicolumn{2}{|l|}{$R^{2}$} & \multicolumn{2}{|c|}{ Adjusted $R^{2}$} & \multicolumn{2}{|c|}{ Standard error } \\
\hline .877 & \multicolumn{2}{|l|}{.769} & \multicolumn{2}{|l|}{.757} & \multicolumn{2}{|c|}{1.07787} \\
\hline \multicolumn{7}{|l|}{$\begin{array}{l}\text { Model } \\
\text { coefficients }\end{array}$} \\
\hline & B & $\begin{array}{l}\text { Standard } \\
\text { error }\end{array}$ & $\begin{array}{l}\text { Standard } \\
\text { beta }\end{array}$ & $\mathrm{T}$ & Significance & VIF \\
\hline (Constant) & 4.426 & .637 & & 6.945 & .000 & \\
\hline SrvSExprsVal & .581 & .249 & .265 & 2.330 & .023 & 4.125 \\
\hline TradSecVal & .465 & .180 & .228 & 2.576 & .013 & 3.579 \\
\hline Corruption & .433 & .121 & .497 & 3.579 & .001 & 1.883 \\
\hline
\end{tabular}

Table 3

Regression model: value dimensions and corruption on e-readiness

Model correlations

\begin{tabular}{llll}
\hline & Corruption & SrvSExprsVal & TradSecVal \\
\hline Corruption & 1 & $.725(* *)$ & $.527(* *)$ \\
SrvSExprsVal & $.725(* *)$ & 1 & $.362(* *)$ \\
TradSecVal & $.527(* *)$ & $.362(* *)$ & 1 \\
\hline
\end{tabular}

**Correlation is significant at the 0.01 level (2-tailed). 


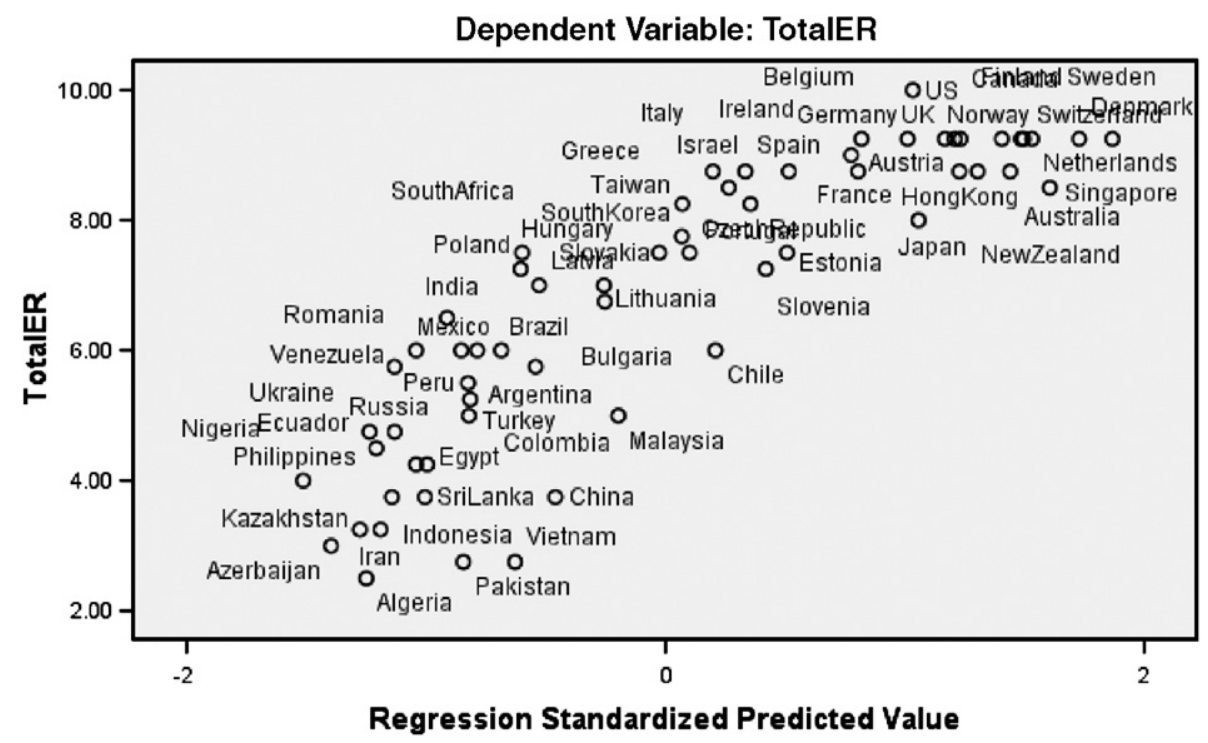

Fig. 2. Plot of the model's predicted e-readiness vs. actual.

economic groups used in the Economist survey (Economist, 2006), namely North America, Western Europe, Asia Pacific, Central and Eastern Europe, Latin America, and Middle East and Africa. Specifically, the 62 countries in the sample were grouped into their economic blocks, and a discriminant analysis was performed using social values (i.e. traditional vs. secular- rational and survival vs. self-expression values) and corruption as the predictors. The first two canonical functions accounted for $98 \%$ of the variance, with the traditional-secular values and corruption dimensions loading primarily on the first discriminant function, and survival-self-expression values loading mainly on the second discriminant function.

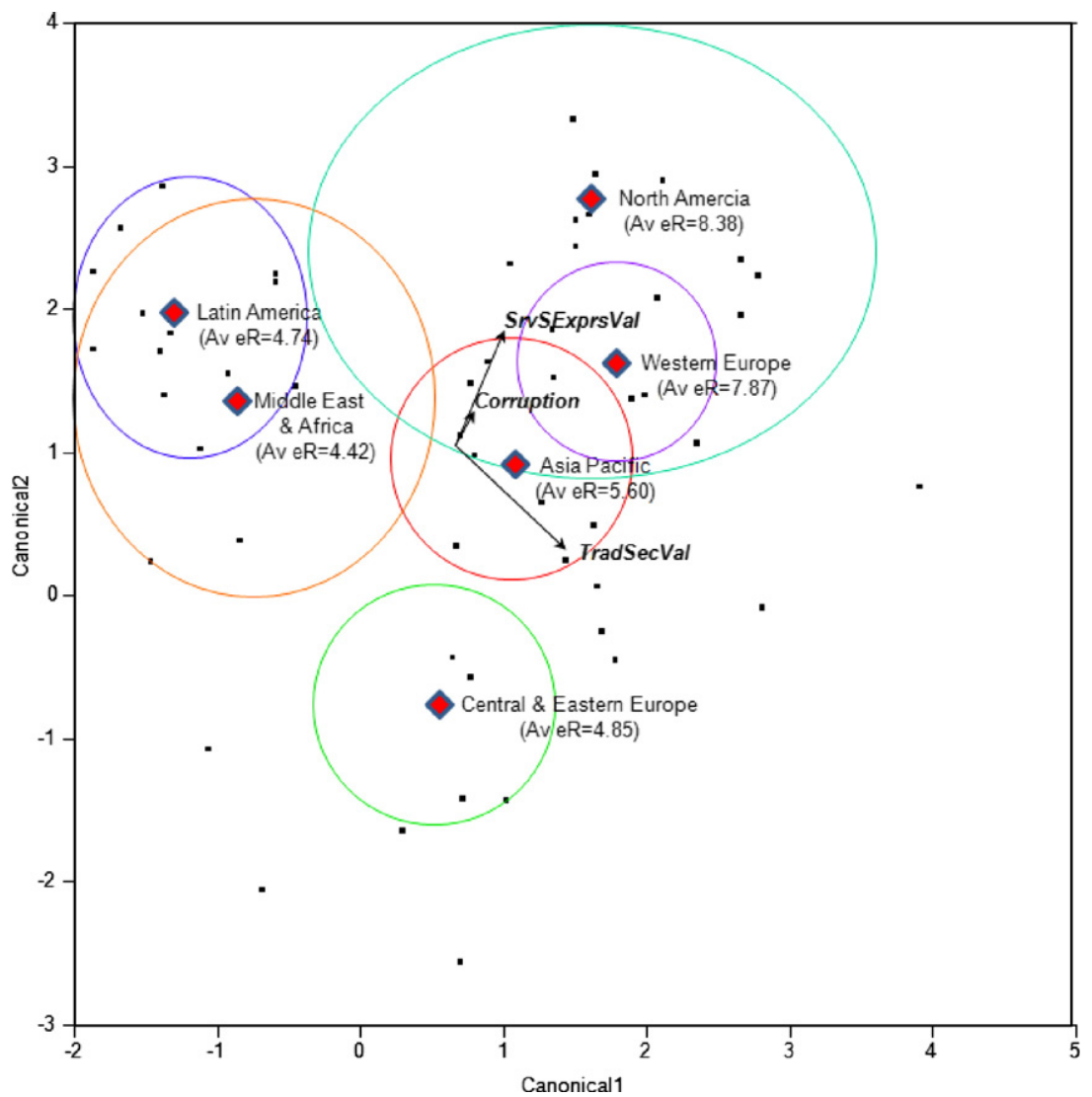

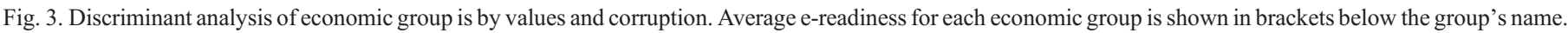


The discriminant plot of the economic groups in the space delineated by the first two canonical functions is shown in Fig. 3. In the plot, the directions in the canonical space of the component variables (traditional-secular and survival-selfexpression values and corruption) are shown by the labeled arrows. The mean for each of the economic groups is marked with a diamond, and the ellipse around each group mean shows the $95 \%$ confidence boundary. Finally, the mean e-readiness score for each group is displayed under the appropriate diamond.

\section{Discussion}

We proposed a relationship between cultural values and objective country-level readiness to engage in trans-national B2B e-commerce. Using measures from the World Values Survey and Corruption Perception Index and the Economist e-readiness survey we found a strong link. Specifically, a nation's e-readiness appears to be strongly influenced by the cultural values held by its citizens. First, a lack of inter-personal and inter-institutional trust, as manifested in corrupt behavior acts as a severe crimp on the development of reliable e-business practice. Simply, corruption in a society not only hampers a nation's e-readiness but also severely corrodes e-business, whilst in contrast the absence of corruption significantly enhances the development of e-commerce. From this we might speculate that is not sufficient to have the technical infrastructure and training in place for international e-commerce to flourish. Technical infrastructure is a necessary but not sufficient condition; nations need to pay attention to the soft aspect of e-business as well as the hard, technical aspects.

Second, perhaps unsurprisingly, the development of ecommerce is related to a country's progression from survival values to those of self-expression. This parallels the shift from early-industrial society to the post-industrial society, and is clearly partly related to economic development. Nations need a critical level of economic and social development before they not only can afford, but will be motivated to build the infrastructure needed for e-commerce. We might hypothesize that this economic barrier is likely to decline sharply in the coming decades, as the cost of technological infrastructure falls.

Third, the development of a nation's readiness to engage in international e-commerce is related to the development of secular-rational values. Anti-liberal values seem to hamper a nation's e-readiness. For example the internet appears to be very threatening to highly authoritarian cultures; indeed such cultures have seen a draconian clamp down in free use of the web, as exemplified by the likes of Pakistan, Iran, and China (Biever, 2007). One might surmise that this is partly because of the fact that nations with traditional values tend to be highly nationalist and relatively insular; this obviously mitigates the openness and global nature of e-commerce.

These results are illustrated in the discriminant plot — Fig. 3. The countries of North America and Western Europe have the highest average scores for e-readiness ( 8.38 and 7.87 respectively), also score high on values of self-expression, moderately on secular values, and low on corruption (recall that higher scores indicated lower corruption). In contrast, the Asia Pacific countries that fall in the middle of the pack in terms of e-readiness (5.56), score moderately on self-expression values, moderately secular values and moderately on corruption. Latin America and the Middle East and Africa have the lowest e-readiness (4.74 and 4.42 respectively), score poorly on self-expression and secular values, but high on corruption. Finally, Central and Eastern Europe which similarly scores rather poorly on e-readiness (4.85), similarly scores lowly on self-expression values, and very high on corruption; however these countries, due to their communist legacy score high on secular values. Thus, scoring high on any one of the three dimensions does not necessitate a high e-readiness; rather e-readiness necessitates progress on all three dimensions before a country is ready for the seeds of e-readiness to flourish.

In terms of policy, one may infer the following in developing an international strategy for e-business. First, North America and Western Europe present the lowest overall risk for developing eB2B relationships: these countries have the technological infrastructure to support e-business, favorable political and economic conditions and a skilled workforce. Moreover, being low in corruption, and having cultures that favor secular and selfexpression values government or third party interference is unlikely. Asia Pacific seems the next best bet for the development of successful e-relationships. Central and Eastern Europe present the unique challenge of having high corruption which is clearly caustic to the development of stable international e-relationships. It is perhaps unsurprising that the majority of viruses, trojans and various internet extortions (denial-ofservice attacks etc.) emerge from the ex-Soviet bloc. Latin America and the Middle East and Africa are still in the process of building the physical, economic, and political infrastructures necessary to provide a stable e-business platform. Transnational e-relationships with some countries in these regions represent a relatively high risk for management. Even if individual companies can overcome the technical issues the extraneous country factors render such ventures challenging.

For example, it is revealing to note that it is often only one variable that's seems to be affected by this in the e-readiness mix. For example, when one considers the e-readiness of South Africa (a total score of 5.74 out of 10 in Table 1), it is obvious that the nation's real problem is that of connectedness (where it scores a dismal 2.70). Despite scoring well on such factors as Legal Policy and Supporting Services, the country's poor connectedness, which is also highly weighted, drags it down to an overall level of e-readiness that places it only in the middle of the competitive field. The Economist Intelligence Unit white paper (2006, p. 17-18) lays the blame squarely at the feet of an ineffective telecoms liberalization effort which condones one of the world's last effective fixed-line monopolies. This in turn is the result of the current government's political agenda - its dependence on and alliance with the trade union movement has hamstrung its efforts to privatize and liberalize telecommunications. Undoubtedly this has had an effect not only on e-business within the country, but on the decisions of B2B marketers in other parts of the world on whether to seek erelationships there or not.

So what lessons do these findings have for managers considering developing trans-national B2B e-relationships? 
First, they should not be swayed merely by the technology the level of corruption within a society can severely retard the efficacy of trans-national e-commerce. Second, culture has a significant impact on a country's ability to engage in international e-commerce. Moreover as culture changes more slowly than technology, the soft values in a society may be an even better predictor of the success of an e-B2B relationship then the hard infrastructure.

One potential criticism of the research design is that the endogenous and exogenous variables are conflated. However, closer inspection reveals that the e-readiness construct is exclusively comprised of objective, country-level statistics and do not measure subjective values which constitute culture and corruption. However, there are limitations to the work presented here. For example, the data used in the research is aggregate-level data which generalizes about a particular country. B2B marketers will find that many of their relationship partners in other lands are exceptions to these broad rules. The data is also taken at a point in time, and while we have used very recent data, situations can change rapidly, particularly in the area of e-readiness. We are also using data that was not collected for our specific purpose - we had no control over its collection, and while we believe that the collection procedures were sound, we cannot vouch for them.

A number of possible future research avenues flow from this work. We hope that our research emphasizes the fact that there are considerable analytical opportunities that exist in the exploration of publicly available data. When data from various credible and independent sources can be combined, and then analyzed, this provides opportunities for B2B scholars and insights for practitioners. The data and the analysis also provide a strong backdrop to a more detailed case analysis of a particular country. For example, if our regression equation were used to calculate the e-readiness of a particular country, the impact of changing values and corruption levels could then be used to predict how e-readiness might change in the future, and whether the climate for these types of changes are currently in place. Obviously, this type of research is amenable to longitudinal extension - by tracking changes in the key variables over time, scholars will be able to map the effects of these, not only on ereadiness but on a host of other variables of interest. Finally, future research might include a range of developmental control variables, such as climate and GDP, to more exactly partition out the impact that values have on e-readiness.

\section{Acknowledgments}

The authors would like to acknowledge the help of the editor, Professor Saeed Samiee and two anonymous reviewers for their help in improving this paper.

\section{References}

Aljifri, H. A., Pons, A., \& Collins, D. (2003). Global e-commerce: A framework for understanding and overcoming the trust barrier. Information Management \& Computer Security, 11(2/3), 130-139.

Avlonitis, G. J., \& Karayanni, D. A. (2000). The impact of Internet use on business-to-business marketing: Examples from American and European companies. Industrial Marketing Management, 29, 441-459.
Biever, C. (2007). Global web censorship on the rise. New Scientist(2606), 22-2302 June.

Brass, L. (2006). RFID revolution. Knight Ridder Tribune Business News, 1 Jun 4.

Burn, J., \& Colin, A. (2005). A dynamic model of e-business strategies for ERP enabled organizations. Industrial Management and Data Systems, 105(8), 1084-1096.

Cousins, K. C., \& Robey, D. (2005). The social shaping of electronic metals exchanges: An institutional theory perspective. Information Technology and People, 18(3), 212-229.

CPI (2005). Corruption perceptions index 2005. Transparency international global coalition. http://www.transparency.org accessed July 21, 2006.

Eckstein, H. (1988). "A culturalist theory of political change". American Political Science Review, 82, 789-804.

Eid, R., Trueman, M., \& Ahmad, A. M. (2002). A cross-industry review of B2B critical success factors. Internet Research, 12(2), 110-124.

Fukuyama, F. (1995). Trust: the social virtues and the creation of prosperity. New York: Free Press.

Génaux, M. (2004). Social sciences and the evolving concept of corruption. Crime, Law and Social Change, 42(1), 13-24.

Hall, E. T. (1959). The silent language. New York, NY: Doubleday.

Hofstede, G. (1980). Culture's consequences: international differences in workrelated values. Beverly Hills, CA: Sage.

Inglehart, R. (1990). Culture shift in advanced industrial societies. Princeton, NJ: Princeton University Press.

Inglehart, R. (1997). Modernization and postmodernization: cultural, economic and political change in 43 societies. Princeton, NJ: Princeton University Press.

Inglehart, R. (2000). Modernization, cultural change, and the persistence of traditional values. American Sociological Review, 65, 19-51.

Inglehart, R., \& Baker, W. E. (2000). Modernization, cultural change and the persistence of traditional values. American Sociological Review, 65, 19-51.

Inglehart, R. \& Long, K. (2002) "Clash of civilizations or trauma of modernization? Support for democracy in Islamic societies." Paper presented at the annual meeting of the Midwest Political Science Association, Chicago, April 25-28, 2002. 30 pp.

Iyer, K., Germain, R., \& Frankwick, G. L. (2004). Supply chain B2B e-commerce and time-based delivery performance. International Journal of Physical Distribution \& Logistics Management, 34(7/8), 645-652.

Joynt, P., \& Warner, M. (1985). Managing in different cultures. Oslo, Norway: Universitetsforlaget.

Karavdic, M., \& Gregory, G. (2005). Integrating e-commerce into existing export marketing theories: A contingency model. Marketing Theory, 5(1), 75-83.

Khatri, N., Tsang, E. W. K., \& Begley, T. M. (2006). Cronyism: A cross-cultural analysis. Journal of International Business Studies, 37(1), 61-75.

Lambsdorff, J. G. (2007). The institutional economics of corruption and reform: theory, evidence and policy. Cambridge: Cambridge University Press.

Mayer, R. C., Davis, J. H., \& Schoorman, F. D. (1995). An integration model of organizational trust. Academy of Management Review, 20(3), 709-735.

OED. (1998). The shorter Oxford english dictionary. Oxford: Oxford University Press.

Olson, J. S., \& Olson, G. M. (2000). i2i trust in e-commerce. Communications of the ACM, 43(12), 41-45.

Park, H. (2003). Determinants of corruption: A cross-national analysis. Multinational Business Review, 11(2), 29-48.

Porter, M. E. (2001). Strategy and the Internet. Harvard Business Review, 79(3), 63-78.

Rao, M. (2003). Checklist for national e-readiness. International Trade Forum, $3,10-13$.

Reddy, A. C., \& Iyer, R. (2002). A conceptual model of the principles governing effective e-commerce. International Journal of Management, 19(3), $517-524$.

Samiee, S. (1998). Exporting and the Internet: A conceptual perspective. International Marketing Review, 15(5), 413-426.

Sanyal, R. (2005). Determinants of bribery in international business: The cultural and economic factors. Journal of Business Ethics, 59(1/2), 139-145.

Smircich, L. (1983). "Concepts of culture and organizational analysis". Administrative. Science Quarterly, 28(3), 339-358. 
Taylor, E. B. (1871). Primitive culture. London, UK: Murray.

The Economist. (2006). Bricks online; E-commerce, 378(8468), 72.

The Economist Intelligence Unit. (2006). The 2006 e-readiness rakings. White Paper, London, UK: The Economist Intelligence Unit.

Tiessen, J. H. (2004). Multinational multilingualism on the Internet: The use of Japanese on corporate web sites. Canadian Journal of Administrative Sciences, 21(2), 180-190.

Transparency International (2006). Corruption surveys and indexes. Transparency international web site (www.transparency.org accessed July 21, 2006).
WVS. (2005). The world values survey. (www.worldvaluessurvey.org - accessed July 21, 2006).

Yap, A., Das, J., Burbridge, J., \& Cort, K. (2006). A composite-model for e-commerce diffusion: Integrating cultural and socio-economic dimensions to the dynamics of diffusion. Journal of Global Information Management, 14(3), 17-36. 